\title{
Konjuge Linoleik Asit ve Sağlık Açısından Önemi
}

\author{
Canan Asal Ulus ${ }^{1}$, Ali Gücükoğlu ${ }^{2 *}$ \\ ${ }^{1}$ Ondokuz Mayıs Üniversitesi, Sağllk Bilimleri Fakültesi, Beslenme ve Diyetetik Bölümü, 55200 Samsun, Türkiye \\ ${ }^{2}$ Ondokuz Mayls Üniversitesi, Veteriner Fakültesi, Besin Hijyeni ve Teknolojisi AbD, 55200 Samsun, Türkiye
}

M A K A L E B İ L G İ S İ

\section{Derleme Makale}

Geliş 07 Ekim 2016

Kabul 22 Kasim 2016

\section{Anahtar Kelimeler:}

Konjuge linoleik asit

Cis9-trans11

Fonksiyonel gida

Sağlık

Hayvansal gida

*Sorumlu Yazar:

E-mail: aligucuk@omu.edu.tr

\section{Ö Z E T}

Bilim ve teknolojideki gelişmeler ve sağlık alanında yapılan araştırmalar beslenmenin insan sağlığının korunmasında olduğu kadar, hastalık durumlarında da tıbbi tedavinin etkinliğini arttırdığı ve bazı hastalıkların tedavilerinde ise tek başına etkili olduğu üzerine yoğunlaşmaktadır. Son yıllarda besleyici özellikleri dıșında metabolizmada fizyolojik yararlar sağlayan ve kronik hastalık riskini azaltabilen 'Fonksiyonel gidalar" olarak adlandırılan besin unsurlarının önemi artmış ve bu gıdalar daha fazla tüketilmeye başlamıştır. Bu fonksiyonel bileşiklerden birisi de son yıllarda büyük ilgi gören ve gerek deney hayvanları gerekse insanlar üzerinde yürütülen çalışmalar sonucu insan sağlığı üzerine önemli etkileri bulunan konjuge linoleik asit (KLA) izomerleridir. KLA'in vücut yağ birikimini azaltıcı etkisi, antidiabetik etkileri, arteriosklerozis riskini azaltıcı, kemik mineralizasyonunu artırıcı ve immun sistemi kuvvetlendirici etkilerinin saptanması ile birlikte son zamanlarda fonksiyonel gıda üretiminin yapısına girmesiyle dikkat çekmeye başlamıştır.

Turkish Journal Of Agriculture - Food Science And Technology, 5(1): 98-102, 2017

Conjugated Linoleic Acid and Importance to Health

\section{A R T I C LE IN F O}

\section{Review Article}

Received 07 October 2016

Accepted 22 November 2016

\section{Keywords}

Conjugated linoleic acid

Cis9-trans11

Functional food

Health

Animal's food

*Corresponding Author:

E-mail: aligucuk@omu.edu.tr

\section{A B S T R A C T}

The development in science \& technology and the researches made in the health field showed that nutrition increases the effectiveness of medical treatment as well as maintaining the human health and singularly effective in the treatment of certain diseases. In recent years, the importance of nutritional elements called 'Functional foods' has increased. Functional foods provide physiological benefits and can reduce the risk of chronic diseases beyond their nutritional benefits. One of these functional compounds is conjugated linoleic acid (CLA) isomers which have significant effects on human health and previously have been demonstrated in the researches carried out on people and animals. CLA's attracted more attention after detection of its body fat accumulation reducing, antidiabetic, immune system enhancing, arteriosclerosis reducing, bone mineralization increasing effects.

\section{Giriş}

Konjuge yağ asitleri (KYA) çoklu doymamış yağ asitlerinin konjuge çift bağlı geometrik ve pozisyonel izomerleridir. KLA, linoleik asitin (cis-9, cis-12oktadekadienoik asit) konjuge pozisyonel ve geometrik izomerlerinin bir karışımıdır (O'Shea ve ark., 1998; Khanal ve Dhiman, 2004). KLA'nın başlica 5 izomeri cis9, cis-11 (c-9, c-11); trans-9, cis-11 (t-9, c-11); trans-9, trans-11 (t-9,t-11); trans-10, trans-12 (t-10, $t-12)$ ve trans-10, cis-12 (t-10,c-12) oktadekadienoik asitlerdir. Daha az bulunan izomerler ise cis-10, cis-11, cis-12 ve ttrans-12 oktadekadienoik asitlerdir. KLA'nın biyolojik aktif izomerleri cis-9, trans-11ve trans-10, cis-12'dir.
KLA izomerlerinin büyük bir kısmını cis-9, trans-11 izomeri oluşturmaktadır (Fritsche ve Steinhart, 1998; O’Shea ve ark., 1998). Bu izomer, "rumenik asit" olarak da adlandırılmaktadır. Rumenik asit, sığır etindeki ve sütteki toplam KLA'nın yaklaşık \%90'ını oluşturmaktadır. KLA'nın tüm cis ve trans izomerik kombinasyonları gıdalarda belirlenmiş olmakla birlikte çoğunlukla KLA izomeri cis-9, trans-11 oktadekadienoik asit şeklinde bulunmakta ve toplam KLA izomerlerinin \%75-80'ini oluşturmaktadır (Bauman ve ark., 1999; Pariza ve ark., 2001). 


\section{Konjuge Linoleik Asit Biyosentezi}

KLA hayvanlardaki biyosentezi, rumende ve endojen olarak dokularda olmak üzere Şekil 1'de gösterildiği gibi iki farklı yerden orijin aldığı bildirilmektedir. Biyosentez basamağının birincisi ruminantların rumenlerinde yemdeki doymamış yağ asitlerinin biyohidrojenasyonu şekillenmekte ve bağırsak yoluyla emilip diğer dokulara ulaşmaktadır. İkinci basamakta ise dokulardaki desaturaz enzimi ile $c-9, t-11$ ve $t-10, c-12$ izomerlerinden KLA sentezlenmektedir (Turuni ve Martin, 2001).

\section{Konjuge Linoleik Asitin Gıda Kaynakları}

KLA'nın en önemli hayvansal kaynağı özellikle geviş getiren hayvanların vücut dokuları ve süt ve süt ürünleridir (Kelly, 2001; Wang ve Jones, 2004; Wahle ve ark., 2004). Ancak izomerlerin miktarları hayvanın rasyonuna, çevresel faktörlere, yaşa, yetiştirme koşullarına, mevsime, tür ve genetik faktörlere göre değişkenlik gösterdiği bildirilmektedir (McGuire ve ark., 1991). Tablo 1'de bazı hayvan türlerinin kas dokularında bulunan KLA miktarı (mg/g yağ) gösterilmektedir.

Ruminant kaynaklı gıdaların yağ içeriğindeki artış, KLA miktarını artırmaktadır. Yine gıdaların üretilirken kullanılan proses ve proses şartları da KLA içeriğini etkilemektedir. Yapılan çalışmalarda, ısıtma, pişirme metodu, seçilen starter kültür, olgunlaşma süresi kullanılan katkı maddeleri gibi etkenlerin KLA içeriğini etkilediği gözlenmiştir (Khanal ve Dhiman, 2004). KLA süt yağı ve kas yağında bulunmaktadır. KLA izomerleri, sığır etindeki toplam yağ asitlerinin yaklaşık \%1'ini ve süt ürünlerindeki toplam yağ asitlerinin $\% 2$ 'sini oluşturmaktadır (Rule ve ark., 2002). c9t11 büyükbaş hayvan yağındaki toplam KLA'in \%57'den \%85'e kadar, süt ürünlerinde $\% 73$ 'den $\% 93$ 'e kadarını oluşturduğundan başlıca izomerdir ve geviş getiren hayvanların rumeninde diyetle alınan linoleik asitin (LA) bakteriyel hidrojenasyonu sonucu olduğu için rumenik asit olarak adlandırılır (Shantha ve Decker, 1993; Kramer ve ark., 1998).

İnsan sütünde bulunan toplam KLA miktarı, inek sütünde bulunan KLA miktarından daha fazla olup; $1 \mathrm{~g}$ yağda $\% 0,37$ ile $\% 0,75$ arasında değișmektedir. Tablo 2'de işlenmiş süt ürünlerindeki KLA miktarları verilmiştir (Fritsche ve ark., 1999).

Bitkisel kaynaklı gıdalarda ise çok düşük miktarlarda bulunabilir. Bitkisel gidalarda rastlanan nar çekirdeğinde bulunan punisik asit, tung yağında bulunan $\alpha$-eleostarik asit ve çuha çiçeği yağında bulunan katalpik asit KLA çeşitlerindendir. Ayrıca bazı deniz yosunlarının da konjuge-enoik ve tetra-enoik yağ asitleri (konjuge eikosapentaenonik asit (KEPA) ve konjuge dokosaheptaenoik asit (KDHA) içerdiği yapılan çalışmalarla bildirilmiştir (Huang ve ark., 2008). Bununla beraber bazı bitkisel sıvı yağlarda da az miktarda KLA bulunmaktadır. Örneğin kanola yağı $0,5 \mathrm{mg} / \mathrm{g}$, ayçiçek yağı $0,4 \mathrm{mg} / \mathrm{g}$, misır yağ $0,2 \mathrm{mg} / \mathrm{g}$ ve zeytinyağ $10,2 \mathrm{mg} / \mathrm{g}$ KLA içermektedir (Ercoşkun ve ark., 2005).

Kümes hayvanları ve yumurtaları da daha az miktarda KLA içermektedir. Hindi eti tavuk etinden daha fazla KLA içerir. Yumurtada KLA genelde sarısında bulunmaktadır (Watkins ve ark., 2001). Su ürünlerinde düşük miktarlarda $(0,1-0,9 \mathrm{mg} \mathrm{KLA} / \mathrm{g}$ yağ arasında) olduğu belirtilmiştir (Chin ve ark., 1992; Shantha ve Decker, 1993; McGuire ve ark., 1999).

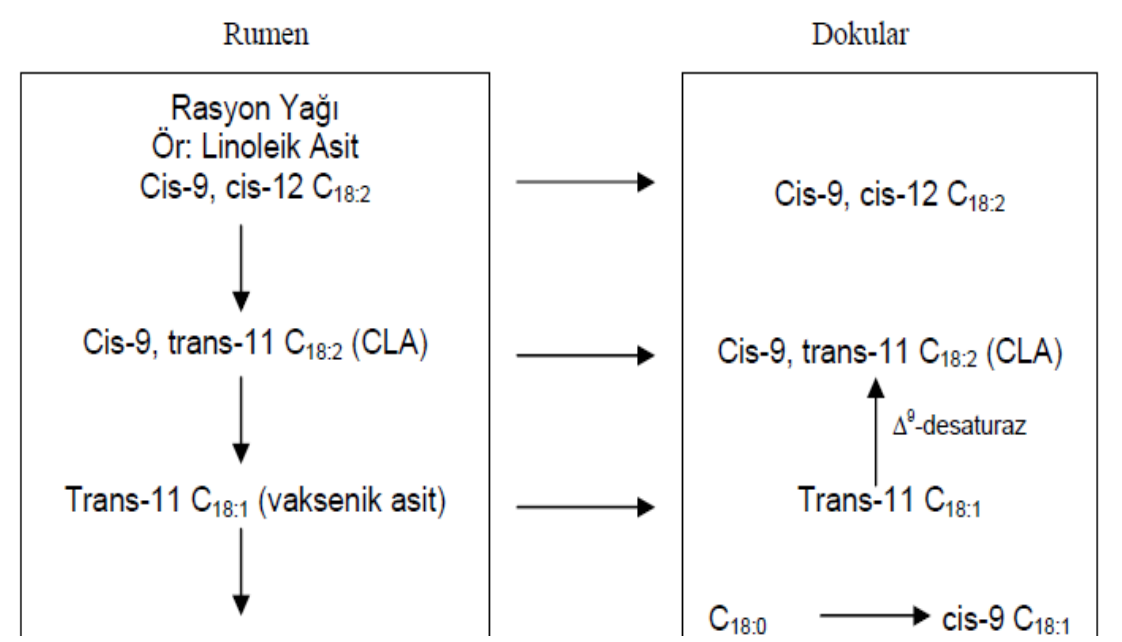

Şekil 1 Linoleik asitin biyohidrojenasyon basamakları (Bauman ve ark., 1999)

Tablo 1 İnsan beslenmesinde kullanılan farklı hayvan türlerindeki KLA miktarı (mg/g yağ)*

\begin{tabular}{l|c}
\hline \multicolumn{1}{c|}{ Hayvan Türü } & Toplam KLA (mg/g yă $)$ \\
\hline Kuzu & $5,6-19,0$ \\
Siğır & $2,9-10,0$ \\
Dana & 2,7 \\
Domuz & $0,6-1,5$ \\
Tavuk & $0,7-1,5$ \\
Hindi & $2,0-2,5$ \\
At & 0,6 \\
\hline
\end{tabular}

*Schmid ve ark. (2006) 
Tablo 2 İșlenmiş bazı süt ürünlerindeki KLA miktarları*

\begin{tabular}{l|cc}
\multicolumn{1}{c|}{ Süt ürünü } & Toplam KLA $(\mathrm{mg} / \mathrm{g}$ yağ $)$ & C9t11 izomeri $(\%)$ \\
\hline Homojenize süt & 5,5 & 92 \\
Tereyağ1 & 4,7 & 88 \\
Yoğurt & 4,8 & 84 \\
Dondurma & 3,6 & 86 \\
Krema & 4,6 & 90 \\
Çeddar peyniri & 3,6 & 93 \\
Düşük yağlı gravyer peyniri & 4,5 & 83 \\
Süzme peynir & 6,1 & 92 \\
Krem peyniri & 3,8 & 88 \\
Mozarella peyniri & 4,9 & 95 \\
Parmesan peyniri & 3,0 & 90 \\
\hline
\end{tabular}

*Chin ve ark. (1992)

\section{Konjuge Linoleik Asitin Vücut Kompozisyonu Üzerine Etkisi}

Yapılan literatür taramalarında KLA'in özellikle beden yağ kitlesi ile beraber diğer metabolizma üzerine etkisinin belirlenmesine yönelik hem deney hayvanları üzerine hem de çeşitli yaş ve cinsiyetteki insanlar üzerine çalışmalar bulunmaktadır. Fare, sıçan ve domuz gibi hayvanlarda yapılan çalışmada da KLA'in 0,5-2 g/100 g diyet ile alımının vücudun yağ içeriğini azalttığ belirtilmiştir (Wahle ve ark., 2004). Bir başka çalışmada KLA'den zengin diyetin sıçanlarda yă̆ hücresi sayısından ziyade boyutunda azalma yaptığı kaydedilmiştir (Azain ve ark., 2000). Bazı araştırmacılar ise \%1 oranında KLA alımının adipositte apoptozisi indükliyerek beyaz yağ dokusu kitlesini azalttığını bildirmişlerdir (Tsuboyama ve ark. 2000). 6 hafta boyunca \%0,5 LA, c9t11 KLA ve t10c12 KLA eklenen diyetle beslenen hamsterler üzerinde yapılan çalışma sonucunda; hamsterların vücut ağırlığında farklilık olmamasina rağmen $\mathrm{t} 10 \mathrm{c} 12$ ile beslenen hamsterlerde yă kütlesinin belirgin oranda azalmış olduğu belirtilmiştir (Navarro ve ark., 2003). Haftada 3 gün 90 dakika süreyle jimnastik egzersizi yapan bireyler iki gruba ayrılmış, 12 hafta boyunca KLA suplementasyon $(1,8 \mathrm{~g} /$ gün izomer karışımı) desteğ alanlarda vücut yağının kontrol (plasebo-KLA suplementasyon desteği almayanlar) grubuna göre azaldı $\breve{g}_{1}$ belirtilmiştir (Thom ve ark., 2001). Gaullier ve ark. (2004), KLA'in uzun süreli etkisini incelemek amacı ile bir yıl boyunca sağlıklı, fazla kilolu veya obez 180 kadın ve erkek gönüllüyü üç gruba ayırarak 1. gruba KLA-serbest yağ asiti, 2. gruba KLA trigliserid ve kontrol grubuna zeytinyağı vermişler ve KLA kullanımının vücut yağ kitlesinde önemli bir azalmaya sebep olduğunu göstermişlerdir. 19-28 yaşlarında vücut geliştirme sporuna yeni başlayan 24 erkek üzerinde yapılan bir çalışmada 6 hafta boyunca sporculara günde 7,2 g KLA takviyesinin vücut geliştirme egzersizlerinin sonunda güç performansında ve biseps genişliğinde artış olurken, yağ kütlesi artmadan vücut ağırlığının arttığı belirtilmiştir (Lowery ve ark., 2000).

\section{Konjuge Linoleik Asitin Kardiyovasküler Hastalıklar Üzerine Etkisi}

Hayvanlarla yapılan birkaç çalışmada KLA izomerlerinin karışımının besinsel eklentilerinin arteriosklerotik lezyonları düşürdüğü gösterilmişir (Lee ve ark., 1994; Nicolosi ve ark., 1997; Kritchevsky ve ark., 2000). Buna rağmen arteriosklerozli fareler üzerinde yapılan bir çalışma da KLA'nın arteriosklerotik lezyonlarda hiçbir etkisinin olmadığı ve hatta onların gelişmesini sağladığı ileri sürülmüştür (Munday ve ark., 1998). Bununla beraber yapılan bir başka çalışmada 22 hafta sonunda kontrol diyeti ve $(0,5 \mathrm{~g} /$ gün) KLA içeren diyet karşılaştırıldığında KLA ile beslenen tavşanların aortlarında arteriosklerozisin daha düşük olduğu görülmüştür (Lee ve ark., 1994). Yapılan bir diğer çalışmada 12 hafta boyunca $\% 20$ süt yağı ile beslenen hamsterlerde diyete \%1 $c 9 t 11$ KLA izomeri eklendiğinde aortik lipid tortusunun belirgin derecede daha düşük olduğu görülmüştür (Valeille ve ark., 2005). Benzer başka bir çalışmada KLA karışımı ve t10c12 izomeri LDL-C ve HDL-C'yi azaltmıştır fakat çok düşük yoğunluklu protein kolesterolünü de (VLDL-C) artırmıştır. c9t11 izomerin ise etkisi görülmemiştir. Metabolik sendromlu obez insanlarda yapilan bir çalışmada 12 hafta boyunca 3,4 g/gün KLA karışımı ya da t10c12 KLA alımiyla HDL-C konsantrasyonu küçülmüştür (Deckere ve ark., 1999).

\section{Konjuge Linoleik Asitin Kanser Üzerine Etkisi}

Araştırmacılar yapmış oldukları in vitro çalışmalarında $110 c 12$ 'nin kolon kanser hücrelerini IGF-II salgılanmasını azaltarak inhibe ettiğini, $c 9 t 11$ izomerinse etkide bulunmadığını göstermiştir (Kim ve ark., 2002). İnsan prostatik karsinom hücreleri enjekte edilmiş fareler üzerinde yapılan çalışmada 14 hafta boyunca linoleik asit eklenmiş ya da normal diyet verilmiş gruplar karşılaştırıldığında diyetsel olarak \%1 KLA alımı lokal tümör ağırlığını ve akciğer metastazını küçültüğü belirlenmiştir (Cesano ve ark. 1998). Sentetik KLA'in antikanserojenik etkisinin fareler üzerindeki etkisinin araştırıldığı çalışmada KLA'in hayvanların çeşitli kısımlarında (deri, kolon, meme bezleri) tümör oluşumunu geciktirdiği ve azalttığı gözlemlenmiştir. Ayrıca cis-9, trans-11 izomerlerinin kimyasal olarak indüklenmiş sıçan meme kanseri üzerinde etkili bir inhibisyon gösterdiği bildirilmektedir (Pariza ve ark., 2001). Bhattacharya ve ark. (2006), KLA'in kanser üzerine etkilerini inceledikleri çalışmalarında, 14 hafta boyunca günlük olarak $\% 1$ oranında tüketilen KLA'in prostat kanserine neden olan tümörün gelişimini az miktarda da olsa engelleyebildiğini tespit etmiştir. KLA'nın ya da onun izomerlerinin göğüs kanseri riskini 
azaltıcı etkisiyle ilgili yapılan bir çalışmada sıçanları 2 hafta boyunca $\% 0,5, \% 1$ ya da \%1,5 KLA eklenmiş diyetle beslemişler ve çalışma sonucunda meme adenokarsinomlarının $\quad \% 60 \quad$ oranında küçüldüğü belirtilmiştir (Ip ve ark., 1991). Beppu ve ark. (2006), yaptıkları çalışmada, KLA izomerlerinin kolon kanserinin gelişimini engelleyici özelliğinin olduğu vurgulamışlardır. Çalışmada, KLA izomerleri arasında 9t,11t izomerinin en güçlü inhibisyon özelligine sahip olduğu tespit etmişlerdir.

\section{Konjuge Linoleik Asitin İmmun Sistem Üzerine Etkisi}

KLA'in makrofajlardan TNF- $\alpha$ ve IL-1 gibi inflamatuar sitokinlerin üretimini azalttığı gösterilmiştir (Song ve ark., 2005). In vivo ve hücre kültürlerinde KLA'in eikozanoidlerin özellikle de ağrı, ödem ve ateş gibi inflamatuar semptomların oluşmasında önemli rolü olan PGE 2 sentezini azalttığ belirtilmiştir (Weis ve ark., 2004). Yapılan bazı araştırmalarda KLA izomerleri, bütillenmiş hidroksi toluen ile aynı düzeyde, $\alpha$-tokoferole göre daha güçlü ve $\beta-21$ karotenden ise iki kat daha fazla antioksidan özellik gösterdiği belirlenmiştir. Özellikle $c 9, t 11$ izomerinin bu etki mekanizmasından sorumlu olduğu ifade edilmektedir (Bauman ve ark., 1999). Sugano ve ark. (1998), KLA ile beslenen siçanlar üzerindeki çalışmalarda tüm etkenlere bağlı olarak gelişen antialerjik mekanizmada görevli IgA, IgG ve IgM konsantrasyonunun yükseldiği, bununla beraber özellikle gıda alerjilerinde ön planda olan IgE seviyesinin azaldığını gözlemlemişlerdir. Bu değerlerin oluşumunu KLA'in alerjik reaksiyonlarda destekleyici etkisinden dolayı olduğunu saptamışlardır.

\section{İnsanlarda Günlük Diyette Alınması Önerilen KLA Miktarı}

Ip ve Scimeca (1995), 70 kg ağırlığındaki bir insanın KLA'in etkilerinden yararlanabilmesi için 3,0 g/gün KLA tüketmesi gerektiğini belirtmişlerdir. Ritzenthaler ve ark. (2001), c9t11 KLA izomerin kansere karş1 koruyucu etkisinin gösterebilmesi için erkeklerde $620 \mathrm{mg}$, kadınlarda ise $441 \mathrm{mg}$ KLA alınması gerektiğini ifade etmişlerdir.

Almanya'da yapılan araştırmada besinsel olarak günlük alınan $c 9 t 11$ KLA izomerinin ortalama miktarının kadınlarda 0,35 g/gün, erkeklerde ise $0,43 \mathrm{~g} /$ gün düzeyinde olduğu bildirilmiştir (Fritsche ve Steinhart, 1998). Yapılan araştırmalarda farklı ülkelerdeki bireylerin besin tüketimleri incelendiğinde KLA tüketiminin Avustralya'da 1500 mg/gün, İngiltere'de 400-600 mg/gün ve Almanya'da ise $400 \mathrm{mg} / \mathrm{gün}$ civarında olduğu kaydedilmiştir (Kurban ve Mehmetoğlu, 2006). Amerikan Tarım Bakanlığı'nın 1994-1996 yılları arasında yürüttüğü besin tüketim araştırması sonuçlarına göre; et tüketen kişilerin diyetlerinde $221 \mathrm{mg} \mathrm{KLA} /$ gün; et tüketmeyen kişilerin ise $102 \mathrm{mg} \mathrm{KLA/gün} \mathrm{olduğu} \mathrm{hesaplanmıştır}$ (Clement ve ark., 2001). Yapılan değerlendirmelerde insanlarda, KLA'in olumlu etki gösterebilmesi için günde $400 \mathrm{mg}$ 'dan daha fazla KLA (cis-9, trans-11)'in diyetle alınması gerektiği, ancak genel beslenme alışkanlıklarıyla vücuda günlük alınan miktarın ortalama 200 mg'ın altında olduğu belirtilmiştir (Ritzenthaler ve ark., 2001).

\section{Sonuç}

Yapılan çalışmalarda KLA'nin sağlık üzerinde yararlı etkilerinin olduğu görülmektedir. KLA'nın iki biyolojik aktif izomeri olan c9t11 ve t10c12 izomerleri ele alındığında c9t11 izomerin antikarsinojenik, t10c12 izomerininde lipit metabolizması ve vücut kompozisyonu üzerine olan etkileri ön plana çıkmaktadır. KLA ile ilgili in vitro hayvan çalışmaları çok sayıda yapılmışken bugüne kadar KLA'in insan sağlığına olan etkileri üzerine çok az sayıda çalışma yapılmıştır. Yapılan çalışmalardan elde edilen sonuçlar da oldukça çeşitlilik göstermektedir.

Klinik insan çalışmalarının yetersizliğine rağmen, diyete KLA ilavesi edilmesi ile vücut yağ yüzdesinde azalma, kas kitlesinde artma görülmektedir. Bununla beraber insanlarda gastrointestinal sistem şikayetleri ve halsizlik görülebildiği, uzun dönem kullanımının karaciğer fonksiyonları, insülin ve glikoz düzeylerini olumsuz etkilemediği belirtilmektedir. Son y1llara kadar elde edilen çalışma sonuçları KLA kullanımının insanlarda henüz açıklık kazanmadığını ve etkileri ile ilgili daha fazla araştırmanın yapılması gerektiğini göstermektedir.

\section{Kaynaklar}

Bauman DE, Bumgard LH, Corl BA, Griinari JM. 1999. Biosynthesis of conjugated linoleic acid in ruminants. Proceedings of the American Society of Animal Science. 15.

Beppu F, Hosokawa M, Tanaka L, Kohno H, Tanaka T. Miyashita, K. 2006. Potent inhibitory effect of trans9, trans11 isomer of conjugated linoleic acid on the growth of human colon cancer cells. J. Nutr. Biochem. 17(12): 830836.

Bhattacharya A, Banu J, Rahman M, Causey J, Fernandes G. 2006. Biological effects of conjugated linoleic acids in health and gisease. J. Nutr Biochem. 17(12): 789-810.

Cesano A, Visonneau S, Scimeca JA, Kritchevsky D, Santoli D. 1998. Opposite effects of linoleic acid and conjugated linoleic acid on human prostatic cancer in SCID mice. Anticancer Res. 18:1429-1434.

Chin SF, Liu W, Storkson JM, Ha YL, Pariza MW. 1992. Dietary sources of conjugated dienoic isomers of linoleic acid, a newly recognized class of anticarcinogens. J. Food Compos Anal. 5:185-197.

Clement IP, Belury, Keefe CL. 2001. Conjugated linoleic acid: Recent advances in disease prevention and management. The American Dietetic Association's Food and Nutrition Conference and Exhibition, USA. 2001.

Deckere EA, Van Amelsvoort JM, Mcneill GP, Jones P. 1999. Effects of conjugated linoleic acid isomers on lipid levels and peroxisome proliferation in the Hamster. Br. J Nutr. 82:309-317.

Erçoşkun H, Uğuz Ş, Kıralan M. 2005. Konjuge linoleik asit. Gıda Mühendisliği Dergisi. (19):42-46.

Fritsche J, Steinhart H. 1998. Analysis, occurrence and physiological properties of trans fatty acids (TFA) with particular emphasis on conjugated linoleic acid isomers (CLA)-a review. Fett/Lipid. 100:190-210.

Gaullier JM, Halse J, Hoye K. 2004. Conjugated linoleic acid supplementation for reduces body fat mass in healthy overweight humans. Am. J Clin Nutr. 79:1118-1125.

Ip C, Chin SF, Scimeca JA, Pariza MW. 1991. Mammary cancer prevention by conjugated dienoic derivative of linoleic acid. Cancer Res. 51:6118-6124. 
Ip C, Scimeca JA. 1995. Opposing effects of cis-9, trans-11 and trans-10, cis-12 conjugated linoleic acid on blood lipids in healthy humans. Nutr. Cancer. 24:241-247.

Kelly GS. 2001. Conjugated linoleic acid: A review. Altern. Med Revie. 6:367-82.

Khanal RC. Dhiman TR. 2004. Biosynthesis of conjugated linoleic acid (CLA): A review. Pakistan J. Nutrition. 3(2):72-81.

Kim YJ, Liu RH. 2002. Increase of conjugated linoleic acid content in milk by fermentation with lactic acid bacteria. J. Food Sci. 67: 1731-1838.

Kramer JKG, Parodi PW, Jensen RG, Mossoba MM, Yurawecz MP, Adlof RO. 1998. Rumenic acid: A proposed common name fort he major conjugated linoleic acid isomer found in natural products. Lipids. 33:835.

Kritchevsky D, Teper SA, Wright S. 2000. Influence of conjugated linoleic acid (CLA) on establishment and progression of atherosclerosis in rabbits. J. Am Coll Nutr. 19: 472-477.

Kurban S, Mehmetoğlu İ. 2006. Konjuge linoleik asit metabolizması ve fizyolojik etkileri. Türk Klinik Biyokimya Dergisi. 4(2): 89-100.

Lee KN, Kritchevsky D, Pariza MW. 1994. Conjugated linoleic acid and atherosclerosis in rabbits. Atherosclerosis. 108:1925.

Lowery LM, Appicelli, PA, Lemon PWR. 1998. Conjugated linoleic acid enhances muscle size and strength gains in novice bodybuilders. Med. Sci Sports Exerc. 30:182.

McGuire MA, McGuire MK, Parodi PW, Jensen RG. 1999. Advances in conjugated linoleic acid. Research. 191:295306.

Munday JS, Thompson KG, James KA. 1999. Dietary conjugated linoleic acids promote fatty streak formation in the C57BL/6 mouse atherosclerosis model. Br. J Nutr. 81:251-255.

Navarro V, Zabala A, Macarulla MT. 2003. Effects of conjugated linoleic acid on body fat accumulation and serum lipids in hamsters fed an atherogenic diet. J Physiol Biochem. 59:193-199.

Nicolosi RJ, Rogers EJ, Kritchevsky D, Scimeca JA, Huth PJ. 1997. Dietary conjugated linoleic acid reduces plasma lipoproteins and early aortic atherosclerosis in hypercholesterolemic hamsters. Artery. 22:266-277.

O'Shea M, Stanton C, Devery R. 1999. Antioxidant enzyme defence responses of human MCF-7 and SW480 cancer cells to conjugated linoleic acid. Anticancer Res. 19:1953-1959.

Pariza MW, Park Y, Cook ME. 2001. The biologically active isomers of conjugated linoleic acid. Prog Lipid Res. 40:283298.
Ritzenthaler KL, McGuire MK, Falen R, Shultz TD, Dasgupta N, McGuire MA. 2001.Estimation of conjugated linoleic acid Intake by written dietary assessment methodologies underestimates actual intake evaluated by food duplicate methodology. J Nutr. 131:1548-1554.

Schmid A, Collomb M, Sieber R, Bee G. 2006. Conjugated linoleic acid in meat and meat products: A review. Meat Science. $73: 29-41$.

Shantha NC, Decker EA, Hennig B. 1993. Comparison of methylation methods fort he quantification of conjugated linoleic acid isomers. J. Assoc Offic Anal Chem Int. 76: 644-649.

Song HJ, Grant I, Rotondo D, Mohede I, Sattar N, Heys SD. 2005. Effect of CLA supplementation on immune function in young healthy volunteers. Eur J Clin Nutr. 59(4): 508517.

Sugano M, Tsujita A, Yamasaki M, Noguchi M, Yamada K. 1998. Conjugated Linoleic Acid Modulates Tissue Levels of Chemical Mediators and Immunoglobulins in Rats. Lipids. 33(5): 521-527.

Dietary manipulations of body fat-reducing potential of conjugated linoleic acid in rats. Bio. Biotechnol Biochem. 65:2535-2541.

Thom E, Wadstein J, Gudmundsen O. 2001.Conjugated linoleic acid reduces body fat in healthy exercising humans. J. Int Med Res. 29: 392-396.

Tsuboyama-Kasaoka N, Takahashi M, Tanemura K. 2000. Conjugated linoleic acid supplementation reduces adipose tissue by apoptosis and develops lipodystrophy in mice. Diabetes. 49:1534-1542.

Turuni ME, Martin JC. 2001. Sources, functions and analysis of conjugated linoleic acid and its metabolites in Structured and Modified Lipids. pp.251-278, Ed. Gustano F. D., Marcel Dekker Inc., New York.

Valeille K, Ferezou J, Amsler G. 2005. A cis 9 trans 11 conjugated linoleic acid rich oil reduces the outcome of atherogenic process in hyperlipidemic hamster. Am. J Physiol Heart Cire Physiol. 289:652-659.

Wahle KW, Heys SD, Rotondo D. 2004. Conjugated linoleic acids: are they beneficial or detrimental to health? Prog. Lipid Res. 43:553-587.

Wang YW, Jones PJ. 2004. Conjugated linoleic acid and obesity control: efficacy and mechanisms. Int. J Obes Relat Metab Disord. 28:941-955.

Weiss MF, Martz FA, Lorenzen, CL. 2004. Conjugated linoleic acid: historical context and implications. Prof. Animal Scientist. 20(2):118-126. 